\title{
RESEARCH AND EVALUATION OF GROWTH RATE MODEL FOR NATIVE CHINESE MOSO BAMBOO
}

\author{
Shen, C. ${ }^{1,2}-$ FenG, Z. $.^{1 *}-$ ChEN, P. ${ }^{1}-$ ChEN, S. ${ }^{1}-$ Ullah, T. ${ }^{3}$ \\ ${ }^{1}$ Beijing Key Laboratory of Precision Forestry, Beijing Forestry University \\ Beijing 100083, China
}

${ }^{2}$ The Third Surveying and Mapping Institute of Guizhou Province, Guiyang 550004, China

${ }^{3}$ School of Nature Conservation, Beijing Forestry University, Beijing 100083, China

*Corresponding author

e-mail:fengzhongke@126.com; phone/fax: +86-138-1030-5579

(Received $17^{\text {th }}$ Sep 2019; accepted $8^{\text {th }}$ Jan 2020)

\begin{abstract}
Tree height growth assessment is important to understand forest dynamics that can reflect the health, productivity, and sustainability of a forest. Tree growth models are important tools to provide a reliable set of information for forest management. Accurate prediction of plant height from time is important for estimating future production. In this study, we used 80 native Moso bamboo and fit 9 models to predict bamboo height as a function of time since sprouting. Our results showed that Logistic growth model was the most suitable for predicting bamboo height ( $\mathrm{r}=0.969)$, and can be used for predicting the growth and yield of mature native Moso bamboo, and provide a basis for the calculating biomass and carbon storage.
\end{abstract}

Keywords: Phyllostachys heterocycla, tree growth, height, growth time, optimal model

\section{Introduction}

Forest ecosystems account for $30 \%$ of the global terrestrial ecosystem. It is the most biologically and genetically diverse ecosystem providing not only habitat to more than $50 \%$ of the world's flora and fauna (Aerts and Honnay, 2011; Keenan et al., 2015; Miura et al., 2015), but also served human all through human history by providing food, water resources and other valuable timber products (Morales et al., 2015; Miura et al., 2015). Forest ecosystems also play an irreplaceable role in curbing global climate change, carbon cycle, soil and water conservation, and sustainable supply and regulation of forest products (Piao et al., 2018). The research and development of the forest growth model can timely and accurately understand the quantity, quality and dynamic changes of forest resources, and provide a basis for the analysis and assessment of forest growth, biomass and forest yield (Köhl et al., 2015).

Tree growth is an important facet of forest dynamics and can reflect the health, productivity, and sustainability of the forest (Zhang et al., 2019), therefore, it is very important to measure it on a regular basis. Tree growth models are important tools in providing reliable information for decision making regarding forest management (Liu et al., 2017). Many tree growth models that can effectively project changes in forest resources have been developed (Cortini et al., 2011; McCullagh et al., 2017). Tree height is the most important factor in forest resource inventory surveys, production and management of forest resources and for research on forest ecosystems (Vargas-Larreta et al., 2009; Xuan et al., 2016). Accurate estimation of tree height is important in the 
development of forest growth models and can be used to estimate stock volume, biomass and carbon stocks (Li et al., 2015).

Tree growth is a complex process that depends on multiple and interacting factors. It is influenced by site conditions (Lévesque et al., 2016), climatic variables (Zell, 2018), and management (Biging and Dobbertin, 1995). Observation of tree height $(\mathrm{H})$ from the ground is usually affected by the complexity of the distribution of understory vegetation, forest density and topography of the terrain (Temesgen et al., 2014). Moreover, the procedure to measure $\mathrm{H}$ is both time and cost expansive. Due to these reasons estimation of $\mathrm{H}$ is relatively more tricky and difficult that $\mathrm{DBH}$ (D) measurement. Because of this difficulty and to reduce the costs associated with field inventories, it is common practice to fit tree models based on D to predict H (Saunders and Wagner, 2008; Paulo et al., 2011). Further, an improved understanding of the H-D relationship is needed for reliable regional and global estimates of forest biomass and carbon storage. An allometric power relationship between $\mathrm{H}$ and $\mathrm{D}$ is often assumed in estimating $\mathrm{H}$, although this approach neglects the possible large deviation in estimating biomass by allometry (Feldpausch et al., 2011; Stark et al., 2013). Besides this, non-linear theoretical functions are often used, such as the Chapman-Richards (Song et al., 2011), Hossfeld (Yen et al., 2010), Logistic, and Gompertz (Richards, 1959; Huang et al., 1992; Zeide, 1993; Cieszewski, 2001).

Bamboo is an important forest resources in many parts of the world. There are more than 70 genera of bamboo that are mainly distributed in tropical and subtropical regions (Zhou, 1992). Bamboo is particularly import in China, which is known as the "kingdom of bamboo". There are more than 40 genera and 400 species of bamboo in China. The Chinese bamboo forest covers 6.01 million ha, mainly distributed in Fujian, Jiangxi, Zhejiang, Hunan, Sichuan, Guangdong, Guangxi, and Anhui provinces (State Forestry Administration, 2014).

Bamboo is the main food for giant pandas, which are a unique and protected species in China (Mertens et al., 2008). Bamboo provides food for humans too. Further, it is a green material that can be used as a substitute and supplement for wood where it is widely used in construction, transportation, papermaking, furniture, and handicraft manufacturing (Tang et al., 2016). Phyllostachys heterocycla (Moso bamboo), which is characterized by its fast growth and rapid biomass accumulation is an important forest type in Southern China (Zhao et al., 2016). These forests cover 4.43 million ha in China, accounting for about $70 \%$ of the national bamboo forest area. The main forest products from Moso bamboo forests are timber and shoots for human consumption. Moso bamboo can reach a height of $20 \mathrm{~m}$ when mature and can grow between 30 and $100 \mathrm{~cm}$ per day during the growing season (Jiang et al., 2002; Chen, 2011). Thus, it has a higher annual carbon sequestration than other common timber trees (Song et al., 2011), suggesting a high potential for carbon storage (Yen et al., 2010).

For these reasons, there is a need to monitor and accurately estimate the biomass of Moso bamboo forests in China. The growth patterns of bamboo are different from trees; its unique characteristics include fast growth, high production and rapid maturation from shoot to culm (Scurlock et al., 2000). Few researchers have addressed the H-D relationship of bamboo using an allometric power equation (Inoue et al., 2011). The H-D relationship of Moso bamboo has only been studied by Inoue (2013), who used reduced major axis regression. Previous studies have mostly focused on biomass and carbon storage, and did not systematically study bamboo height. In this paper we use the bamboo height data to develop a growth model for Moso bamboo. Such an equation is useful for quantifying bamboo biomass and carbon storage. 


\section{Materials and methods}

\section{Study area}

The study area is located near Yixing City and Wuxi City in southwest Jiangsu Province, adjacent to the Zhuhai Scenic Area (N 31 ${ }^{\circ} 25^{\prime}$ and E 119 $73^{\prime}$ ). The area has a higher elevation and mountainous in the south and lower in elevation and relatively flat in the north, the range of the DEM is -137 614 m (Fig. 1). The area called "the ocean of bamboo" in Chinese. The area falls within the subtropical monsoon climate region, with abundant rainfall all year round. The average annual number of rainy days is 136.6 , and the annual average precipitation is $1177 \mathrm{~mm}$ (Wu and Ming, 2007). The rainfall is concentrated in spring and summer, although it is warm and humid throughout much of the year. The annual average temperature is $15.7^{\circ} \mathrm{C}$, the average frost-free period is more than 240 days, and the growth period is up to 250 days. The rivers cris-cross the study area and the average annual precipitation is $1177 \mathrm{~mm}$. The soil is mainly yellow in colour with abundant organic matter providing excellent conditions for the growth of bamboo (Peng and Zou, 2011).

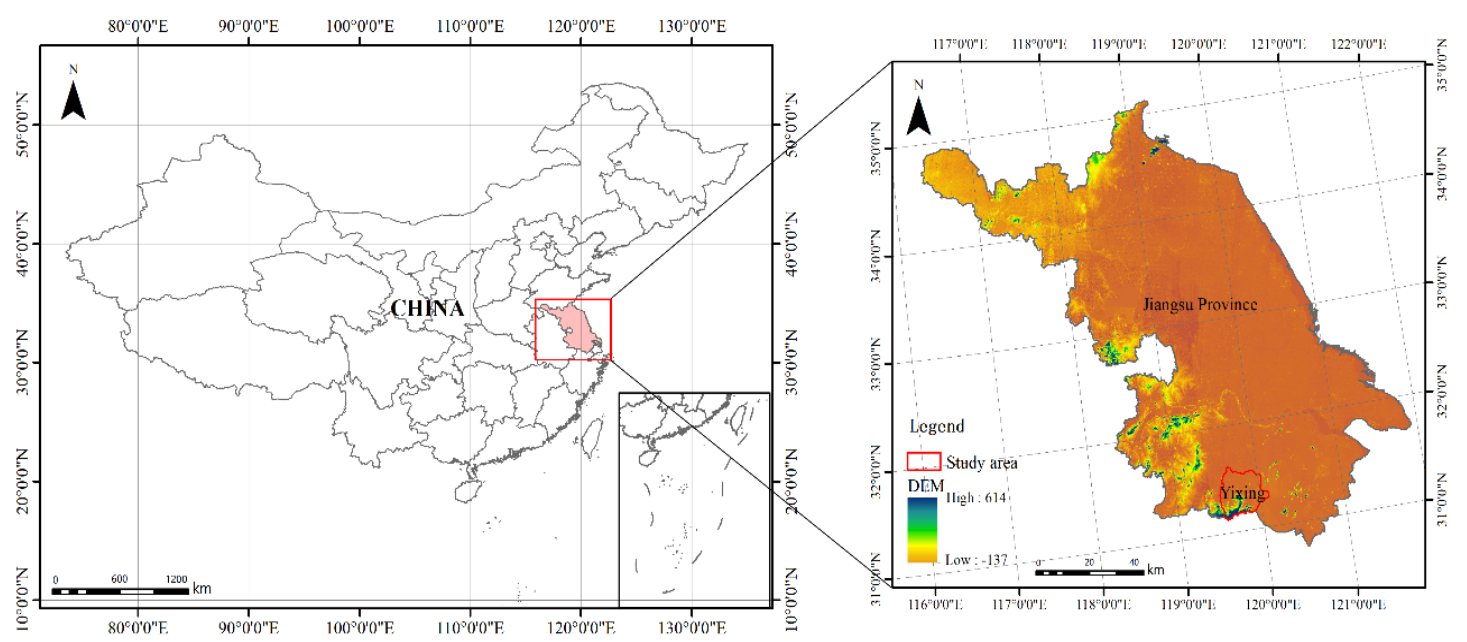

Figure 1. Location and digital elevation model (DEM) of the study area

\section{Data acquisition}

Five plots $\left(15^{*} 15 \mathrm{~m}\right)$ were set up in the study area, and 20 bamboo shoots were randomly selected from each sample plots. Shoots that died or which were damaged by animal foraging or vandalism were removed from the data set, eighty bamboo shoots were left from sample plots in the study area as measurement samples, shoots were identified for measurement on March 26, 2015, and visited at regular intervals. By May 22, the shoots began to grow in height. Height growth was completed after 56 days. When the shoot height was less than $2 \mathrm{~m}$, height was measured by a tape; when the shoot height exceeded $2 \mathrm{~m}$, the height references were accurately measured by total station (Leica Flexline TS06plus Total Station) with accuracy to the millimetre level. The complete height recorded after the growth ranged from $10.71 \mathrm{~m}$ to $16.06 \mathrm{~m}$.

The models used were nonlinear and fit using the statistical package SPSS 20.0 (SPSS for Windows version 20.0) and the Levenberg-Marquardt (LM) method. 


\section{Tree height models assessment}

We selected nonlinear models such as tree growth empirical equations and theoretical equations to compare the performance of the model. All model formulas refer to the reference (Meng, 2006). The model formulas were shown in Table 1.

Table 1. Selected tree height models

\begin{tabular}{c|c|c}
\hline Number & Model & Formula \\
\hline Model 1 & Logistic & $h=\frac{A}{1+b e^{-c t}}$ \\
\hline Model 2 & Richard & $h=A\left(1-e^{-b t}\right)^{c}$ \\
\hline Model 3 & Gompertz & $h=A e^{-b e^{-r t}}$ \\
\hline Model 4 & Schumacher & $h=A e^{-b / t}$ \\
\hline Model 5 & Sloboda & $h=A e^{-b e^{-c t^{d}}}$ \\
\hline Model 6 & Roляcp & $h=A t^{b} e^{-c t}$ \\
\hline Model 7 & Weibull & $h=A\left(1-e^{-b t}\right)^{c}$ \\
\hline Model 8 & Power function & $h=A t^{b}$ \\
\hline Model 9 & Korf & $h=A e^{-b t^{-c}}$ \\
\hline
\end{tabular}

H: Moso bamboo's height, m; t: time, day; a-d are parameters

\section{Model evaluation}

In order to verify the accuracy of the forecasting accuracy of the above methods, we validated the models. Usually the model is validated by independent data sets, which is the best way to validate the model at present (Zhang et al., 2019). The majority of the data $(80 \%)$ was used for model calibration, and the remaining $(20 \%)$ data was used for verifying the consistency of the models. At present, this method of model validation has been applied in many model validation, such as the biomass model, DBH growth model and carbon storage model (Zhang et al., 2019). Model evaluation mainly used the following indicators: root mean squared error (RMSE), adjusted coefficient of determination $\left(\mathrm{R}^{2}{ }_{\mathrm{adj}}\right.$ ), and other criteria (Montgomery, 2013). RMSE combines the variation of mean deviation and deviation, and can directly and clearly evaluate the accuracy of the model. RMSE and $\mathrm{R}^{2}$ are important evaluation factors in this paper. The closer the $\mathrm{R}^{2}$ value is to 1 , the better the fitness of the model is (Peng et al., 2001). However, Cameron and Windmeijer (1997) suggested that the coefficient of determination $\left(\mathrm{R}^{2}\right)$ is not suitable for model evaluation of non-linear functions. Therefore, this paper uses six indicators to evaluate it comprehensively (Burnham and Anderson, 2002) including: root of mean square error (RMSE), coefficient of determination $\left(\mathrm{R}^{2}\right)$ and adjusted coefficient of determination $\left(\mathrm{R}^{2}{ }_{\text {adj }}\right.$ ), bias (BIAS) and relative bias (BIAS $\left.{ }_{\text {rel }}\right)$, residual sum of squares (RSS), Akaike's Information Criterion (AIC). The smaller the RMSE value, the higher the predicted accuracy. The large of $R^{2}$ and $R^{2}$ adj value, and correlation is stronger. AIC is an information standard commonly used to choose the best model. The expressions of the statistics are shown as follows: 


$$
\begin{gathered}
R M S E=\sqrt{\frac{\sum_{i=1}^{n}\left(h_{i}-\hat{h}_{i}\right)}{n-p-1}} \\
R^{2}=1-\frac{\sum_{i=1}^{n}\left(h_{i}-\hat{h}_{i}\right)^{2}}{\sum_{i=1}^{n}\left(h_{i}-\bar{h}_{i}\right)^{2}} \\
R_{\text {adj }}^{2}=1-\left(1-R^{2}\right) \times \frac{n-1}{n-p-1} \\
B \operatorname{ias}=\frac{\sum_{i=1}^{n}\left(\hat{h}_{i}-h_{i}\right)}{n} \\
B \operatorname{ias}_{\text {rel }}=\frac{\sum_{i=1}^{n}\left(\hat{h}_{i}-h_{i}\right) / h_{i}}{n} \times 100 \\
R S S=\sum_{i=1}^{n}\left(h_{i}-\hat{h}_{i}\right)^{2} \\
A I C=n \ln (R S S)+2(p+1)-n \ln (n)
\end{gathered}
$$

where $h_{i}$ is the observation value; $\hat{h}_{i}$ is the forecast value and $\bar{h}_{i}$ is the average value; $n$ is the total number of data used to the fitted model; and $p$ is the number of independent variables.

\section{Results}

Non-linear regression analysis was performed by SPSS. The model estimated all the parameters by using the calibration data, and obtained the parameters and $\mathrm{R}^{2}$ values of each model (Table 2). Except for model 9, all of them showed relatively satisfying results. Therefore, it can be seen that model 9 is not suitable for this data. As shown in Table 2, Model 1-8 uses all the data to estimate the parameters by nonlinear regression. All parameters are significant ( $1<0.05)$, and the parameters of each model are easily obtained by calculation except model 9 .

Table 2. Parameter estimates and fitting statistics of the models using all data

\begin{tabular}{c|c|c|c|c|c}
\hline Parameter & a & b & c & d & $\mathbf{R}^{\mathbf{2}}$ \\
\hline Model 1 & 1553.94 & 142.43 & 0.135 & & 0.969 \\
Model 2 & 1946.97 & 7.73 & 0.06 & & 0.964 \\
Model 3 & 1891.38 & 10.05 & 0.066 & & 0.965 \\
Model 4 & 5506.07 & 72.04 & & & 0.961 \\
Model 5 & 2181.55 & 51.33 & 0.596 & 0.523 & 0.963 \\
Model 6 & 0.389 & 2.206 & 0.011 & & 0.953 \\
Model 7 & 2357.07 & 0.000 & 2.482 & & 0.960 \\
Model 8 & 0.893 & 1.859 & & & 0.949 \\
Model 9 & 605.285 & 4.867 & 1637.086 & & 0.06 \\
\hline
\end{tabular}

a-d are model's parameters 
According to the above test formula, each test index value is calculated using the calibration data and the verification data, and the results are shown in Table 3.

Table 3. Calibration data and validation data adaptive statistics for models

\begin{tabular}{c|c|cccc|cccc}
\hline \multirow{2}{*}{ No. } & \multirow{2}{*}{ Variables } & \multicolumn{5}{|c|}{ Fitting data } & \multicolumn{4}{c}{ Validation data } \\
\cline { 3 - 10 } & & bias(m) & RMSE(m) & AIC & Adj. $\mathbf{R}^{\mathbf{2}}$ & bias(m) & RMSE(m) & AIC & Adj. $\mathbf{R}^{\mathbf{2}}$ \\
\hline 1 & h,t & -0.66 & 4.26 & 187.55 & 0.9689 & -0.96 & 3.05 & 38.73 & 0.9836 \\
2 & h,t & -2.38 & 4.57 & 196.42 & 0.9643 & -2.68 & 3.52 & 43.25 & 0.9782 \\
3 & h,t & -2.88 & 4.52 & 195.07 & 0.965 & -3.17 & 3.44 & 42.55 & 0.9792 \\
4 & h,t & -1.37 & 4.75 & 201.54 & 0.9613 & -1.66 & 3.72 & 45.04 & 0.9757 \\
5 & h,t & -2.61 & 4.63 & 198.03 & 0.9634 & -2.90 & 3.60 & 44.01 & 0.9772 \\
6 & h,t & -0.45 & 4.75 & 215.40 & 0.9613 & -0.75 & 4.34 & 50.01 & 0.9668 \\
7 & h,t & -0.22 & 4.63 & 204.26 & 0.9634 & -0.07 & 3.75 & 45.33 & 0.9752 \\
8 & h,t & 1.80 & 5.3 & 219.08 & 0.9519 & 1.50 & 4.45 & 50.77 & 0.9652 \\
\hline
\end{tabular}

\section{Model fitting and evaluation}

Using the Origin8.1, the growth model was fitted by the Levenberg-Marquardt (LM) method. The fitting effects of Model 1, Model 2, Model 3, Model 4 and Model 8 were good (Fig. 2). Other models adopt nonlinear regression, and the fitting results werenon-convergence, which was not suitable for the prediction of this data. In the subsequent statistics, the statistical results of the unconverging model were removed.
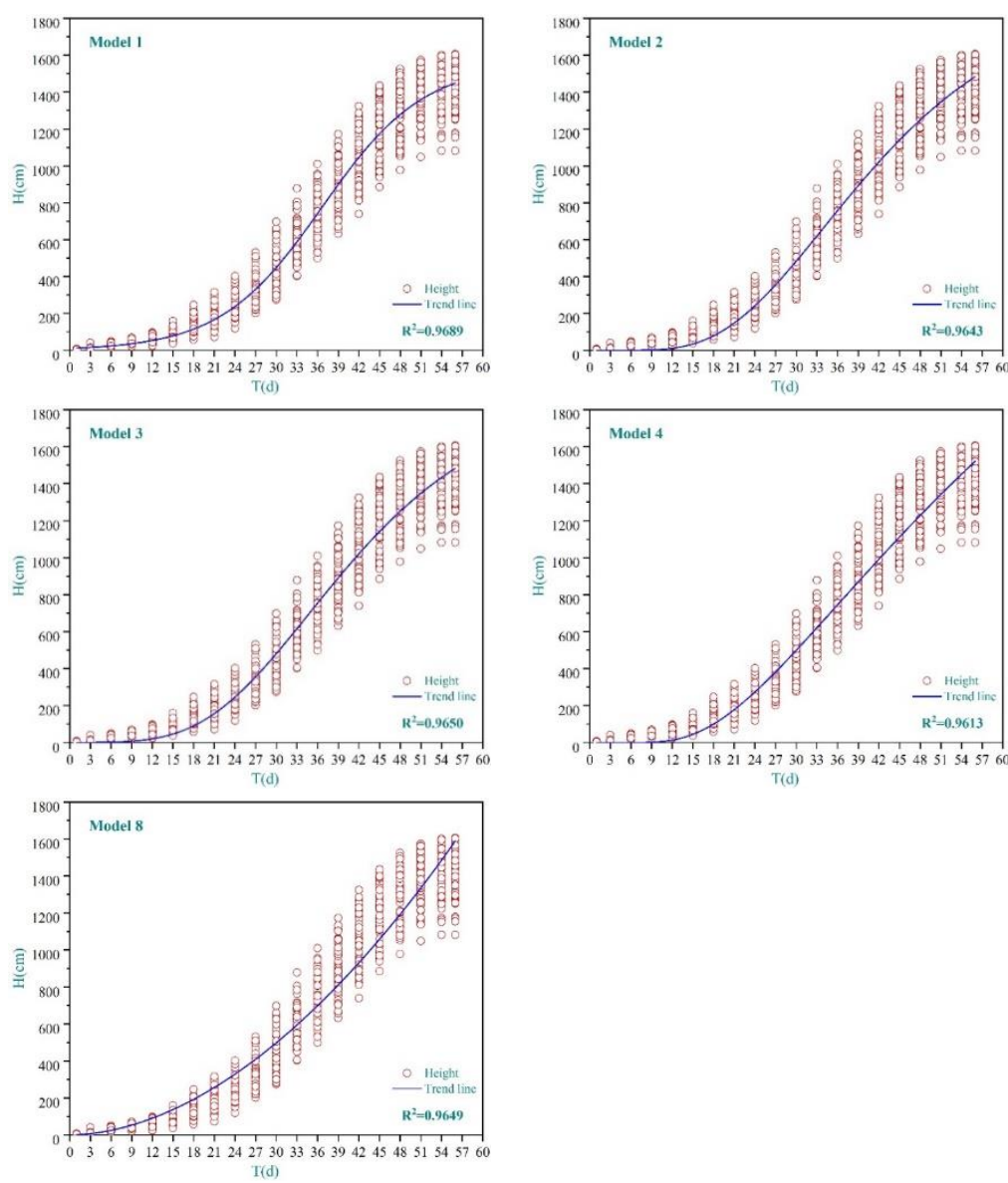

Figure 2. Models fitting trend line 
It can be seen from the above trend graph that bamboo's height and the growth time have a high correlation, and models $1,2,3,4$ and 8 have higher $\mathrm{R}^{2}$ values: $0.9689,0.9643$, $0.9650,0.9613$ and 0.9649 , respectively. The correlation coefficient of Model 1 was the highest observed, and the result obtained in the fitting of the calibration data has the highest precision, which is suitable for the estimation of bamboo's height growth and conforms to the law of tree growth curve.

As shown in Fig. 3, the models 1, 2, 3, 4, and 8, respectively, use the calibration data to obtain the residual of the predicted height, and most of the data points are distributed around $y=0$. These models show the full uniformity of the predicted values and the independence of the residuals. The residual distribution of model 1 in the figure is relatively small, which reveals model 1 is the best model in the study.
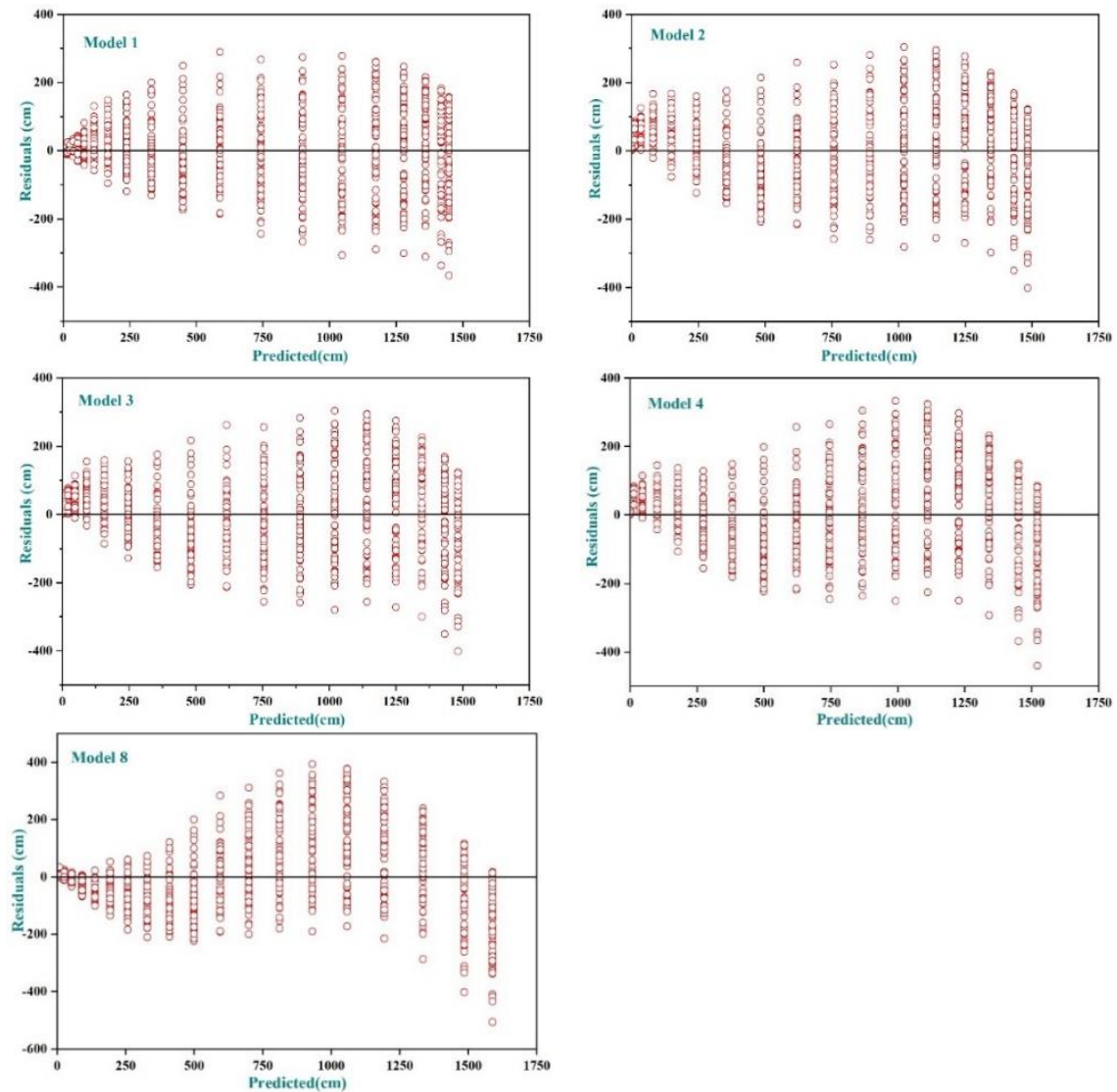

Figure 3. Residual plots in the calibration dataset for the models (Model 1; Model 2; Model 3; Model 4; Model 8)

As shown in Fig. 4, the models 1, 2, 3, 4, and 8 use the verification data to obtain the average deviation value and RMSE of the bamboo height through the growth period. The standard deviations of models $1,2,3,4$ and 8 are mainly distributed around $y=0$, in which the standard deviation of model 8 is $1.61 \mathrm{~m}$, and deviations of most model are less than $1 \mathrm{~m}$, accounting for $93 \%$ of all deviations. The RMSE values of models $1,2,3,4$ and 8 are between 0.049-1.86, the RMSE of model 8 varies greatly, the RMSE value of model 1 changes little, and the model is relatively stable. According to the above analysis, the model 1 is the most suitable model in the calibration data and the verification data among the five models. 

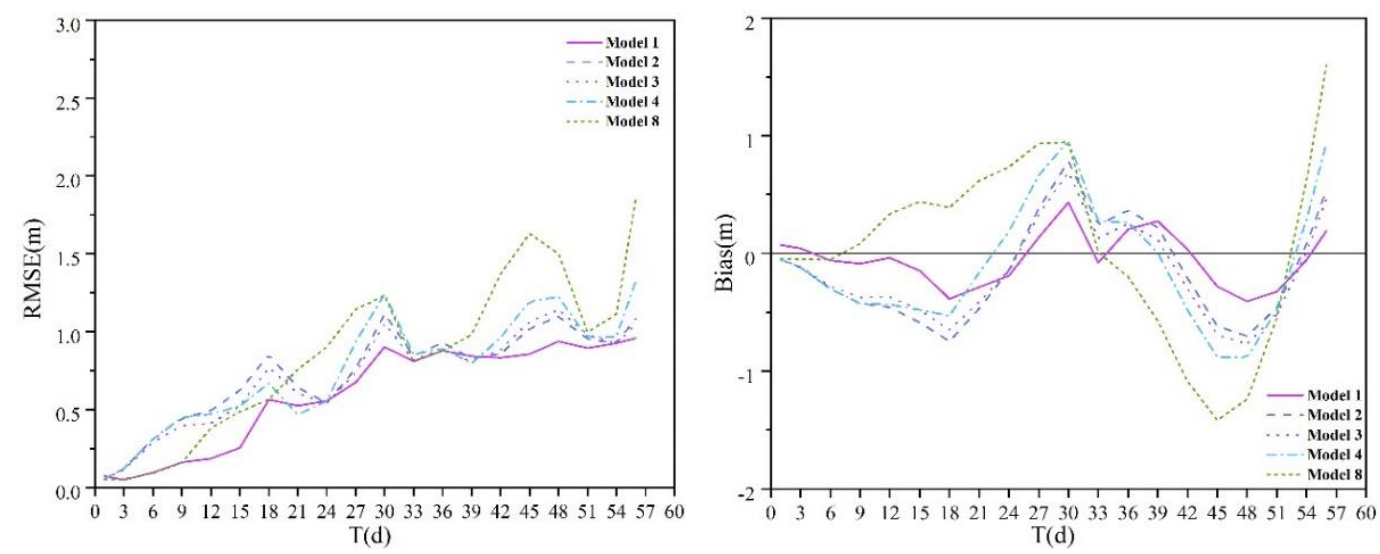

Figure 4. Values of average RMSE and Bias in relation to $T$ in the calibration and validation datasets for the models (Model 1; Model 2; Model 3; Model 4; Model 8)

\section{Discussion}

In this study, based on the tree-based growth model, a model suitable for bamboo height and time was selected, which is very important for predicting the change of bamboo growth height with time. Tree growth is an important manifestation of the dynamic changes of forests, which can provide a basis for forest productivity and temporal and spatial changes in forests. The tree height and DBH models are the most basic and effective models in the growth model. The choice of models should be based on the arrangement of the expression of models with calibration data and validation data (the adjusted $\mathrm{R}^{2}, \mathrm{R}^{2}$, RMSE, the absolute deviation, the relative deviation and the AIC). The model with the adjusted $\mathrm{R}^{2}, \mathrm{R}^{2}$ value closest to the highest value and a deviation (absolute and relative deviation) closest to zero is thought to be the best. The lower the value of RMSE and AIC, the higher the ranking of the model. For each model, its final ranking is the sum of the statistics of the five evaluation values. The model with the minimum sum (i.e., the highest ranking) is considered to be the functional model that is most suitable for estimating the growth of Moso bamboo. According to this analysis, the calibration data and the validation data show that model 1 is the most suitable for estimatingthe growth rate.

In comparison with previous studies, Huang et al., 1992) developed the HT-DBH functional model of the main tree species from 20 weighted nonlinear equations. It was observed that Weibull, Modified Logistic, Chapman-Richards and Schnute functions generally provided the most satisfactory results. Zhang (1997) concluded that the Schnute, Weibull and Chapman-Richards models provided the best predictive performance for 10 conifer species in the inland regions of the United States in the six nonlinear growth functions selected for HT-DBH. Peng et al. (2001) and Sharma and Parton (2007) recommended Chapman-Richards, Weibull, and Schnute nonlinear growth functions as the most satisfactory models in total height predictions in Canada. Ahmadi et al. (2013) reported that Chapman-Richards, Weibull and Schnute functions in predicting accurate total height predictions in Iranian Hyrcanian forests have shown excellent predictive performance, based on mathematical features, biological interpretation of parameters.

Furthermore, Lumbres et al. (2013) reported that the Modified Logistic nonlinear growth function was the best model for the Pinus kesiya Royle ex Gordon of Benguet in 
Philippines. Based on the result of the researchers, nonlinear growth functions are reliable in the prediction of total height of trees. In the latest study of Lumbres et al. (2015) entitled DBH-height modeling and validation for Acacia mangium and Eucalyptus pellita, the Weibull and Chapman-Richards models were observed as the best nonlinear growth functions for Acacia mangium. However, the result of our study suggested that the Logistic regression model has the highest accuracy in predicting the growth of bamboo among the nine models we selected, which is obviously different from the previous research results.

\section{Conclusion}

In this study, the bamboo was used as the object, and the measured data of the fixed sample plots were used. The nonlinear regression method was used to model 80 bamboo shoots randomly seletected in five different study plots. Considering the interrelation between the growth time of bamboo and bamboo's height, the tree growth and empirical equations were used to establish a height growth model of bamboo. From the modeling results, the conclusions are showed as follow. Using the models 1, 2, 3, 4 and 8 to predict the bamboo height, the majority of the bamboo height determination coefficient $\mathrm{R}^{2}$ can reach 0.9 or more, and in terms of accuracy the model 1 performance was the best. The methods and the models recommended in this study are based on statistics, which provide a reliable basis for the estimation of forest growth and survival and planting management for Chinese native Moso bamboo.

Acknowledgements. The research reported in this manuscript is funded by the Fundamental Research Funds for the Central Universities (Grant No. 2015ZCQ-LX-01), the National Natural Science Foundation of China (Grant No. U1710123).

\section{REFERENCES}

[1] Aerts, R., Honnay, O. (2011): Forest restoration, biodiversity and ecosystem functioning. - Annals of Occupational and Environmental Medicine 11: 1-10.

[2] Ahmadi, K., Alavi, S. J., Kouchaksaraei, M. T., Aertsen, W. (2013): Non-linear heightdiameter models for oriental beech (Fagus orientalis Lipsky) in the Hyrcanian forests, Iran. - Biotechnologie Agronomie Société Et Environnement 17: 431-440.

[3] Biging, G. S., Dobbertin, M. (1995): Evaluation of Competition Indices in Individual Tree Growth Models. - Forest Science 41: 360-377.

[4] Burnham, K. P., Anderson, D. R. (2002): Model selection and multimodel inference: A practical. - Springer Berlin Heidelberg. doi:10.1088/1751-8113/44/8/085201.

[5] Cameron, A. C., Windmeijer, F. A. G. (1997): An R-squared measure of goodness of fit for some common nonlinear regression models. - Journal of Econometrics 77: 329-342.

[6] Chen, S. L. (2011): Thoughts on related problems of mulched technique with organic materials in moso bamboo forest for early shooting. - Journal of Zhejiang A \& F University 28: 799-804.

[7] Cieszewski, C. J. (2001): Three methods of deriving advanced dynamic site equations demonstrated. - Canadian Journal of Forest Research 31: 165-173.

[8] Cortini, F., Filipescu, C. N., Groot, A., Dan, A. M., Nunifu, T. (2011): Regional Models of Diameter as a Function of Individual Tree Attributes, Climate and Site Characteristics for Six Major Tree Species in Alberta, Canada. - Forests 2: 814-831. 
[9] Feldpausch, T. R., Banin, L., Phillips, O. L., Baker, T. R., Lewis, S. L., Quesada, C. A., Affum-Baffoe, K., Arets, E. J. M. M., Berry, N. J., Bird, M. (2011): Height-diameter allometry of tropical forest trees. - Biogeosciences 8(5): 7727-7793.

[10] Huang, S. M., Titus, S. J., Wiens, D. P. (1992): Comparison of Nonlinear Height Diameter Functions for Major Alberta Tree Species. - Canadian Journal of Forest Research 22: 12971304.

[11] Inoue, A., Sakamoto, S., Suga, H., KitaharaI, F. (2011): Estimation of culm volume for bamboo, Phyllostachys bambusoides, by two-way volume equation. - Biomass and Bioenergy 35: 2666-2673.

[12] Inoue, A. (2013): Culm form analysis for bamboo, Phyllostachys pubescens. - Journal of Forestry Research 24: 525-530.

[13] Jiang, Z. H., Wang, G., Fei, B. H., Yu, W. J. (2002): The Research and Development on Bamboo/Wood Composite Materials. - Forest Research 15: 712-718.

[14] Keenan, R. J., Reams, G. A., Achard, F., Freitas, J. V. D., Grainger, A., Lindquist, E. (2015): Dynamics of global forest area: Results from the FAO Global Forest Resources Assessment 2015. - Forest Ecology and Management 352: 9-20.

[15] Köhl, M., Lasco, R., Cifuentes, M., Jonsson, Ö., Korhonen, K. T., Mundhenk, P., Navar, J. D. J., Stinson, G. (2015): Changes in forest production, biomass and carbon: Results from the 2015 UN FAO Global Forest Resource Assessment. - Forest Ecology and Management 352: 21-34.

[16] Lévesque, M., Walthert, L., Weber, P. (2016): Soil nutrients influence growth response of temperate tree species to drought. - Journal of Ecology 104: 377-387.

[17] Li, Y. Q., Deng, X. W., Huang, Z. H., Xiang, W. H., Yan, W. D., Lei, P. F., Zhou, X. L., Peng, C. H. (2015): Development and Evaluation of Models for the Relationship between Tree Height and Diameter at Breast Height for Chinese-Fir Plantations in Subtropical China. - Plos One 10: e0125118.

[18] Liu, M., Feng, Z., Zhang, Z., Ma, C., Wang, M., Lian, B.-1., Sun, R., Zhang, L. (2017): Development and evaluation of height diameter at breast models for native Chinese Metasequoia. - Plos One 12: e0182170.

[19] Lumbres, R. I., Lee, Y. J., Calorajr, F., Parao, M. (2013): Model fitting and validation of six height-DBH equations for Pinus kesiya Royle ex Gordon in Benguet Province, Philippines. - Forest Science and Technology 9: 6.

[20] Lumbres, R. I. C., Lee, Y. J., Yun, C. W., Chang, D. K., Kim, S. B., Son, Y. M., Lee, K. H., Won, H. K., Jung, S. C., Seo, Y. O. (2015): DBH-height modeling and validation for Acacia mangium and Eucalyptus pellita in Korintiga Hutani Plantation, Kalimantan, Indonesia. - Forest Science and Technology 11: 119-125.

[21] McCullagh, A., Black, K., Nieuwenhuis, M. (2017): Evaluation of tree and stand-level growth models using national forest inventory data. - European Journal of Forest Research 136: 251-258.

[22] Meng, X. Y. (2006): Forest Mensuration. - China Forestry Publishing House: 179-187.

[23] Mertens, B., Hua, L., Belcher, B., Ruiz, M. (2008): Spatial patterns and processes of bamboo expansion in Southern China. - Applied Geography 28: 16-31.

[24] Miura, S., Amacher, M., Hofer, T., San-Miguel-Ayanz, J., Ernawati, Thackway, R. (2015): Protective functions and ecosystem services of global forests in the past quarter-century. Forest Ecology and Management 352: 35-46.

[25] Montgomery, D. C. (2013): Introduction to Linear Regression Analysis. - Fifth Edition Set, American Statistician 57: 67-67.

[26] Morales-Hidalgo, D., Oswalt, S. N., Somanathan, E. (2015): Status and trends in global primary forest, protected areas, and areas designated for conservation of biodiversity from the Global Forest Resources Assessment 2015. - Forest Ecology and Management 352: 68-77.

[27] Paulo, J. A., Tomé, J., Tomé, M. (2011): Nonlinear fixed and random generalized heightdiameter models for Portuguese cork oak stands. - Annals of Forest Science 68: 295-309. 
[28] Peng, C., Zhang, L., Liu, J. (2001): Developing and Validating Nonlinear Height Diameter Models for Major Tree Species of Ontario's Boreal Forests. - Northern Journal of Applied Forestry 18: 87-94.

[29] Peng, J. Y., Zou, S. M. (2011): Feasibility research on karst cave national geopark construction in Yixing of Jiangsu. - Journal of Geology 2011-01.

[30] Piao, S., Huang, M., Zhuo, L., Wang, X., Ciais, P., Canadell, J. G., Kai, W., Bastos, A., Friedlingstein, P., Houghton, R. A. (2018): Lower land-use emissions responsible for increased net land carbon sink during the slow warming period. - Nature Geoscience 11: 739-743.

[31] Richards, F. J. (1959): A Flexible Growth Model for Empirical Use. - Journal of Experimental Botany 10: 290-301.

[32] Saunders, M. R., Wagner, R. G. (2008): Height-diameter models with random coefficients and site variables for tree species of Central Maine. - Annals of Forest Science 65: 203203.

[33] Scurlock, J. M. O., Dayton, D. C., Hames, B. (2000): Bamboo: An Overlooked Biomass Resource? - Biomass and Bioenergy 19: 229-244.

[34] Sharma, M., Parton, J. (2007): Height-diameter equations for boreal tree species in Ontario using a mixed-effects modeling approach. - Forest Ecology and Management 249(3): 187198.

[35] Song, X., Zhou, G., Hong, J., Yu, S., Fu, S., Li, W., Wang, W., Ma, Z., Peng, C. (2011): Carbon sequestration by Chinese bamboo forests and their ecological benefits: Assessment of potential, problems, and future challenges. - Environmental Reviews 19(1): 418-428.

[36] Stark, H., Nothdurft, A., Bauhus, J. (2013): Allometries for Widely Spaced Populus ssp. and Betula ssp. in Nurse Crop Systems. - Forests 4: 1003-1031.

[37] State Forestry Administration (2014): China Forest Resources Report (2009-2013). - China Forestry Publishing House, Beijing: 6-8.

[38] Tang, X., Fan, S., Qi, L., Guan, F., Manyi, D., Zhang, H. (2016): Soil respiration and net ecosystem production in relation to intensive management in Moso bamboo forests. Catena 137: 219-228.

[39] Temesgen, H., Zhang, C., Zhao, X. H. (2014): Modelling tree height-diameter relationships in multi-species and multi-layered forests: A large observational study from Northeast China. - Forest Ecology and Management 316: 78-89.

[40] Vargas-Larreta, B., Castedo-Dorado, F., Álvarez-González, J. G., Barrio-Anta, M., CruzCobos, F. (2009): A generalized height-diameter model with random coefficients for uneven-aged stands in El Salto, Durango (Mexico). - Forestry 84: 445-462.

[41] Wu, S. J., Ming, W. W. (2007): Preliminary study on surface pollen flora in the Longchi Mountain nature reserve, Yixing, Jiangsu Province. - Acta Palaeontologica Sinica 46: 340346.

[42] Xu, H., Sun, Y., Wang, X., Fu, Y., Dong, Y., Li, Y. (2014): Nonlinear mixed-effects (NLME) diameter growth models for individual China-Fir (Cunninghamia lanceolata) trees in Southeast China. - Plos One 9(8): e104012.

[43] Xuan, G., Li, Z., Yu, H., Jiang, Z., Chen, W., Yu, Z., Qi, L., Lei, S. (2016): Modeling of the height-diameter relationship using an allometric equation model: a case study of stands of Phyllostachys edulis: ecosystem management. - Journal of Forestry Research 27: 339347.

[44] Yen, T. M., Ji, Y. J., Lee, J. S. (2010): Estimating biomass production and carbon storage for a fast-growing makino bamboo (Phyllostachys makinoi) plant based on the diameter distribution model. - Forest Ecology and Management 260: 339-344.

[45] Zeide, B. (1993): Analysis of Growth Equations. - Forest Science 39: 594-616.

[46] Zell, J. (2018): Climate Sensitive Tree Growth Functions and the Role of Transformations. - Forests 9: 382.

[47] Zhang, L. J. (1997): Cross-validation of non-linear growth functions for modelling tree height-diameter relationships. - Annals of Botany 79: 251-257. 
[48] Zhang, H., Feng, Z., Chen, P., Chen, X. (2019): Development of a Tree Growth Difference Equation and Its Application in Forecasting the Biomass Carbon Stocks of Chinese Forests in 2050. - Forests 10: 582.

[49] Zhao, J. C., Su, W. H., Fan, S. H., Cai, C. J., Zhu, X. W., Peng, C., Tang, X. L. (2016): Effects of various fertilization depths on ammonia volatilization in Moso bamboo (Phyllostachys edulis) forests. - Plant Soil and Environment 62: 128-134.

[50] Zhou, F. C. (1992): The State of Utilization, Trend and strategies for the World Bamboo Industry. - World Forestry Research 1992-01. 